\title{
Políticas do SUJeITO E RELAÇÕES DE GÊNERO: RE-SIGNIFICANDO A CIDADANIA ${ }^{1}$
}

Maria Lúcia da Silveira

\section{Introdução}

\section{$A$}

pesquisa na qual baseou-se este artigo, partiu da preocupação com a diversificação da abordagem de gênero nos anos 90, acompanhando a trajetória de grupos de mulheres que fazem diferentes usos do gênero. Nesse sentido, procurou-se estabelecer um diálogo com algumas entidades mediadoras do potencial de ação que o feminismo, alimentado pela perspectiva de gênero, carrega.

Pautei-me para proceder à escolha das entidades, pelo critério da diversidade de espaços de atuação, mas que buscassem atingir mulheres dos setores populares; que apreendessem algumas das múltiplas formas de subordinação das mulheres na sociedade, e, ao mesmo tempo, refletissem um repertório feminista comum; que buscassem, embora o façam de maneira distinta, iniciativas de ação que visassem repercutir em espaços sociais variados para além do próprio espectro do movimento de mulheres, quais sejam, movimento popular, sindical, de direitos humanos, pastorais católicas e movimento negro.

Assim, o foco central deste trabalho são as práticas desenvolvidas pelas entidades selecionadas, que se tornaram o fio condutor que segui procurando analisar a hipótese de um potencial de interpelação societal da cidadania que elas desencadeariam .

Escolhi para essa interlocução quatro entidades feministas de São Paulo, quais sejam, as Católicas pelo Direito de Decidir- CDD; o Geledés, Instituto da Mulher Negra ${ }^{2}$; a União de Mulheres de São Paulo e o SOF - Sempre Viva Organização Feminista . Desses quatro 
grupos, três se caracterizam como Organizações Não Governamentais - ONGs, e um, a União de Mulheres, se define como entidade do movimento de mulheres.

As Católicas pelo Direito de Decidir - CDD, mesmo sendo uma ONG nova e pequena, surgida em 1993, busca desconstruir o peso da religião na subordinação das mulheres, servindo de contraponto à hierarquia da igreja católica. Apresenta-se como uma outra referência, que permite às mulheres desconstruir a culpa que pesa sobre elas diante de escolhas que dizem respeito à sexualidade e aos direitos reprodutivos. Evidentemente, seu público alvo não se limita às mulheres católicas, mas às mulheres em geral, para as quais a influência normatizadora da Igreja pesa fortemente. Nesse sentido, refletem um processo de combinação recente entre feminismo e religião (Rodhen, 1995).

O Geledés, Instituto da Mulher Negra, também é uma organização não-governamental, surgida em 1988, que ao privilegiar a organização de mulheres negras, abriu um debate no interior do movimento de mulheres e do movimento negro, tornando públicas as imbricações entre racismo e sexismo na sociedade. Procura criar um espaço identitário e solidário para as mulheres negras, como base para a possibilidade de auto-organização coletiva. Embora o centro de decisão política esteja na mão das mulheres que o dirigem, possui um serviço jurídico, o SOS Racismo, cujo público-alvo é a população negra em geral, supostamente suscetível às práticas raciais discriminatórias presentes na sociedade.

O Programa de Saúde da Mulher Negra do Geledés foi o espaço de experimentação de novas práticas junto às mulheres. Suas principais coordenadoras estão, hoje, na ONG Fala Preta, criada a partir de 1997.

A União de Mulheres de São Paulo - U.M., constitui-se num referencial na luta das mulheres por direitos. Criada em 1981, vem também de uma longa história de ligação com o movimento popular, onde empreendeu iniciativas junto às mulheres das classes populares. Atualmente, tornou-se referência indispensável na luta contra a violência de gênero, embora trabalhe com um amplo espectro de lutas feministas.

A SOF, cuja sigla significava Serviço de Orientação à Família, existe desde final da década de 60. Quando surgiu, prestava 
atendimento médico às mulheres de baixa renda. Posteriormente, na década de 80 , redefiniu sua atuação e passou a apresentar-se como entidade de assessoria do movimento popular, enfatizando a dimensão político-educativa, junto, sobretudo, aos movimentos de saúde. Demonstra em sua atuação a necessidade de desenvolver a especificidade da saúde da mulher, o que vem a ser a chave para uma perspectiva feminista.

O que tem caracterizado a atuação recente da SOF é uma deliberada tentativa de levar o feminismo para espaços mistos, defendendo a auto-organização das mulheres e chamando atenção para as relações de gênero aí presentes, que aparecem mescladas às relações de classe e raça/etnia. A SOF privilegiou, enquanto espaço de atuação, os movimentos sociais da área popular e sindical, com destaque para os movimentos de saúde, e diversificou, na década de 90 , suas áreas de atuação com parcerias e assessorias junto ao movimento sindical. Expandiu também suas propostas de formação de gênero entre as ONGs.

É preciso enfatizar ainda que esses quatro agrupamentos (ou entidades) estudados têm em comum uma interlocução geral no campo do feminismo, o que garante um repertório temático comum, embora com ênfase e, por vezes, enfoques diferenciados e conflitivos. Por exemplo, todos eles participam da Rede Feminista de Saúde e Direitos Reprodutivos; um deles da Rede contra a Violência contra as Mulheres e da Rede Afro-Caribenha de Mulheres Negras. Todos se fizeram representar no Fórum Paralelo da IV Conferência Mundial da Mulher, em Pequim, e dos Encontros Feministas mais recentes.

Esta pesquisa trabalhou com a hipótese central de que as mulheres organizadas enquanto sujeito são capazes de conformar e consolidar um campo de negociação, compartilhando de uma ética de intervenção pública, apostando na diminuição das desigualdades e exclusões contemporâneas fortemente marcadas por traços de gênero, classe, raça/etnia que se reforçam mutuamente em padrões societários opressivos. A ação desses sujeitos se pauta, portanto, por um sentido emancipatório novo, pela recriação de um campo de possibilidades onde se potencializa a luta pela cidadania. Atenho-me, neste artigo, aos significados teóricos da emergência destes sujeitos. 


\section{Gênero: uma interpelação societal da cidadania}

O alargamento dos campos sociais de luta pela emancipação passa, particularmente, pela incorporação das transformações ocorridas na nossa história recente, engendradas pela constituição das mulheres como sujeito coletivo. Nesse processo, configura-se uma interpelação societal da cidadania.

Pôde-se localizar, na análise dos itinerários dos sujeitos da pesquisa, a energia de suas práticas em interpelar relações em âmbitos variados da vida social. Tal energia é originária, sobretudo, do casamento fecundo entre a constituição de subjetividades e a cidadania.

Ao pensarmos pelo ângulo de uma interpelação societal da cidadania, é possível escapar da armadilha da postura liberal, que a limita a um status legal que se atinge de uma vez por todas. Se aceitamos sua instabilidade é porque consideramos que ela se assenta numa práxis de sujeitos concretos que enfrentam relações de força na sociedade.

Nutrindo-se das práticas, sob a perspectiva de gênero, o campo ético-político dos movimentos sociais poderá carrear mais vitalidade à sociedade civil e fornecer a energia necessária à constituição de uma esfera pública democrática. Isso seria possível, sobretudo, pela ligação inovadora da subjetividade à cidadania, aproximando, assim, o foco de atenção política para captar a construção dos sujeitos.

A diversificação das abordagens de gênero que tentei trazer à tona em suas características centrais - por meio de um modo de retratar os itinerários de quatro agrupamentos feministas -, mostrou como, através de suas práticas, tais grupos desvendam mecanismos de ocultamento das formas de subordinação e hierarquização das mulheres em nossa sociedade. A partir disso, é possível estudar quais concepções alternativas de poder podem ser geradas nas experiências sociais cotidianas de luta.

Os valores do feminismo, renovados pela compreensão do significado amplo das relações de gênero no conjunto das relações sociais, puderam penetrar e expandir-se nos grupos organizados de base de muitos movimentos e organizações; em algumas políticas públicas que engatinham no campo da saúde e no enfrentamento da violência, etc.

As práticas feministas, observadas nesses quatro (hoje, cinco) agrupamentos estudados, chama a atenção por seus experimentos de 
inovação social e superam práticas anteriores de grupos que consideravam o feminismo isolado e separado do resto da sociedade e de suas instituições. Hoje, o discurso e as práticas feministas dirigemse a amplos setores e espaços sociais.

As entidades mediadoras são centros autônomos de ação; contudo, transitam em espaços comuns a um campo de intervenções sociais mais amplo. Não abrem mão da construção de instituições justas que, para tanto, devem levar em conta relações de classe, gênero, raça/ etnia e, ampliando o espectro, considerando relações diversas como as de nacionalidade, de religião, de geração, de ecologia.

A idéia básica, subjacente à análise em curso, é que a multiplicidade dos caminhos e modos de mudança na sociedade traz, em seu bojo, a conformação de identidades individuais e coletivas, as quais podem constituir-se em sujeitos.

As mediadoras da ação coletiva das mulheres, ao torná-las agentes de criação social e de participação ativa na cidadania, levando em conta a interface entre a subjetividade e a cidadania, instauram novas tentativas de comunicação com o outro na experiência de lutas.

Nessa práxis de cidadania, a solidariedade advinda do esforço de combinação da igualdade e da diferença, parte do reconhecimento mútuo dos diferentes sujeitos. Por isso, as mulheres que vivenciam a subordinação em diferentes esferas da vida, na medida em que a encaram sob a óptica de gênero, pleiteiam o seu reconhecimento como sujeito.

Nesse sentido, a luta das mulheres, das minorias étnicas, raciais e sexuais, neste século que quase termina, trouxe embutido a capacidade de introduzir e manejar os conflitos advindos de seus desafios às fronteiras da cidadania dita universal.

A capacidade de engendramento de conflitos inevitáveis, resultantes da emergência desses sujeitos, tem produzido uma inquietação saudável dentro do campo dos movimentos sociais, que acabam por sinalizar para novos projetos de vida coletiva, em condições de esboçar as conexões perdidas entre ética e política.

Enfim, a instauração de outros referenciais para as mulheres, que permitem expandir as alternativas de prática pessoal e social e as possibilidades de luta para conquistá-las, são um capital construído pelas entidades feministas estudadas. 
Novos princípios de inteligibilidade para a ação coletiva das mulheres e um discurso argumentativo que interpela em favor da reconfiguração dos padrões de transformação social são, acima de tudo, desde já, pleiteadores de reconfiguração das formas de sociabilidade em todos os níveis.

Buscou-se, ao partir de práticas emancipatórias concretas, interpretar seus diferentes itinerários de gênero como expressão e formulação do que Heller (1982) chamou de necessidades radicais. No caminho, o alargamento dos referenciais de cidadania foram sendo construídos, inspirados nos inúmeros percursos subjetivos e coletivos de muitas mulheres que hoje despendem o melhor de suas energias e capacidades para resgatar a política, no sentido que Freire Costa a define, ou seja, como a "capacidade de imaginar mundos melhores", não apenas para um futuro remoto, mas a partir do presente.

O alargamento do campo de visão da perspectiva emancipatória tem partido da consciência da opressão e estimulado ações coletivas, passando por um roteiro que percorre a democratização dialógica da vida pessoal e coletiva. E esse roteiro tem sido escrito por mediadoras da ação organizada das mulheres na nossa sociedade.

A possibilidade de enxergar a interpelação que as práticas analisadas fazem à cidadania, permitindo re-significá-la, advém da exploração de uma trilha analítica, qual seja, a tentativa de não amarrar a concepção de cidadania a uma visão restrita do político.

As múltiplas interpelações à cidadania que podem ser conflitantes, muitas vezes, porquanto originárias de segmentos sociais subalternizados na sociedade em confronto com setores sociais que sustentam visões formais da mesma, deixa-nos, no entanto, o rastro da constituição de identidades multifacéticas.

Assim, dessa perspectiva, a cidadania tornar-se-ia o veículo de uma práxis relacional que as relações de gênero, classe, raça/etnia mediatizam. Nesse sentido, a identidade política e culturalmente forjada pelos sujeitos combina com a ação estratégica da cidadania, configurando uma cidadania societal (Donati, 1995).

A constituição e expressão de identidades de gênero, raça/etnia, classe, com suas afinidades e diferenças podem tornar-se, mediante políticas do sujeito, uma força viva de constituição de uma esfera pública democrática.

O sujeito mulheres, nesse sentido, permite que, do interior de 
práticas concretas, sob a perspectiva de gênero, se configure um agir como sujeito calcado numa experiência de individuação e numa consciência de pertencimento, ou seja, de identidade de grupo.

O sentido das práticas, que as entidades feministas estudadas engendram, apontam para a articulação de uma vontade de individuação a uma ação coletiva. $\mathrm{O}$ ativismo das mulheres surpreende pela capacidade de conexão entre a vida pessoal e coletiva.

A semeadura dessas práticas nas redes movimentalistas da sociedade civil tem sido, a meu ver, uma reatualização criativa da ligação entre políticas da vida e políticas emancipatórias.

Uma rede de relações, que tem se estabelecido entre as mulheres que mediam práticas no interior de entidades variadas, evidencia $\mathrm{o}$ potencial enorme que possuem para a alimentação e renovação de projetos democráticos radicais em nossa sociedade.

Contudo, há que se perguntar sobre a eficácia e a capacidade de agir sobre as desigualdades, subordinações e exclusões desses sujeitos em constituição. Essa é uma questão eminentemente política a esperar encaminhamentos novos, atualmente ainda não descortinados, diante dos conflitos no campo ético-político dos movimentos sociais.

Do ponto de vista teórico, fica claro que uma permanente conceitualização de cidadania deve levar em conta os feixes de relações sociais nos quais as relações de gênero jogam um papel relevante. A cidadania societal emergente não pode apagar as diferenças identitárias, mas renegociá-las partindo da expressão pública dessas experiências.

A concepção clássica da cidadania (liberal-burguesa), como forma típico-ideal de um contrato social, pode ser revista em favor dos laços societais que conectam a cidadania aos sujeitos concretos. Uma práxis de cidadania emerge desse percurso teórico se a virmos como princípio e veículo de articulação, seja do antagonismo, seja do diálogo.

Assim, resgata-se o dinamismo da cidadania que pode refazer sobretudo a ligação entre Estado e sociedade civil, num patamar participativo e radicalmente democrático.

Uma cidadania multifacetada forjada em novas formas de se fazer política tem um apelo normativo sinalizador para a construção de uma esfera pública democrática. Desse modo, a cidadania pode se tornar veículo dinâmico de projetos emergentes na sociedade. 
As práticas de cidadania das mulheres, nas diversas redes movimentalistas, enfrentando diferentes lutas, engendram uma carga de reflexividade nas várias relações que se quer transformar, ampliando e radicalizando o repertório político.

Ainda que conflitivas, ou mesmo antagônicas ao status quo dominante, o apelo relacional da cidadania projeta novos cenários e novos repertórios para a interação entre os diferentes sujeitos na cena pública.

Evidentemente, para que essa noção de cidadania subjacente em diversas práticas de gênero (não só delas, mas em algumas ecológicas, dentre outras) se instaure dentro do cotidiano das instituições e da cultura política, deve-se levar em conta o esforço de toda uma época que apenas se abre. O que se vislumbra são possibilidades a serem trabalhadas num campo democrático e a aposta num projeto renovado de emancipação.

\section{As práticas de gênero como políticas geradoras de novos agenciamentos para uma cidadania multifacetada}

É aceitável afirmar, seguindo os percursos de entidades feministas mediadoras, que as práticas que levam em conta o gênero, por sua abertura inclusiva, relacional e transversal, reinscrevem o sujeito como pilar central de conformação de identidades políticas com a finalidade de repensar projetos emancipatórios da sociedade.

Esse sujeito que é múltiplo, para tornar-se coletivo, necessita levar em conta diversas clivagens entrecruzadas, correspondentes a diferentes posições que vivencia na vida social. Contudo, para forjar uma identidade política coletiva, terá que enfrentar a construção de um patamar comum de unidade com outros sujeitos nas lutas contra a desigualdade e a exclusão, o qual não está dada a priori, nem assegurado socialmente.

Um projeto coletivo contemporâneo necessitaria, portanto, ser pensado, de um lado, sem dissolver a possibilidade de um discurso coletivo para as mulheres enquanto sujeito político e, de outro, pensando a garantia de um espaço para a articulação de distintas identidades.

Ao contrário dos que pensam a pluralidade baseada na dispersão, a práxis de cidadania empreendida no campo de um ativismo feminista de múltiplos vetores indica um potencial dessa cidadania societal que venho 
tentando discutir, e cuja apropriação política poderá tornar-se chave na estruturação de um novo projeto de transformação social.

Contudo, se quisermos falar em sujeito coletivo hoje, teremos que aproximar o foco da multiplicidade de sujeitos situados, considerando-se os pólos históricos de dominação e exploração sobretudo os de classe, raça/etnia e gênero.

A diversidade de experiências que conformam um sujeito no plano pessoal, grupal, e num coletivo mais amplo, em seus enfrentamentos com poderes excludentes, coloca-nos, cada vez mais, diante dos desafios de encarar os obstáculos para a construção de uma subjetividade livre, articulando os diferentes planos acima mencionados.

A via do sujeito e da subjetividade pode nos levar ao reestabelecimento das "conexões perdidas entre ética e política", que segundo Giddens $(1994 ; 1996)$ são a base para uma democracia dialógica. Dito de outro modo, a partir da conformação das mulheres como sujeito, forjado num processo que garanta espaço para a confluência da experiência pessoal e coletiva das mesmas; experiência essa tornada simultaneamente social, moral e política, é que se pode recuperar a dimensão ética da política do sujeito.

Essa via do sujeito é, nos termos de Touraine (1997), uma política do sujeito que, respaldada na abordagem histórica que se quer aqui privilegiar, pode traduzir perfeitamente o sentido das práticas feministas estudadas.

A articulação necessária de não se perder o sujeito pessoal no coletivo, ou seja, a aproximação do foco no sujeito, no sentido que lhe dá Giddens, de "controle da narrativa do self", permite desvendar o esforço empreendido por essas práticas feministas de construção de autonomia das mulheres.

Assim, valoriza-se o lado ativo, a constituição da vontade do sujeito individual numa prática comunicativa (contemplando o outro, o coletivo), do que apenas o lado passivo, constituído, da cidadania. Como diz um dos textos do Geledés, explicando o esforço dos grupos de auto-ajuda: "vamos nos salvar juntas". Tal apelo significa afirmar que é necessário um processo de individuação, que nada tem a ver com o individualismo egóico.

Na pesquisa realizada, parte-se do mundo vivido para reconstruir uma experiência social coletiva. Esse procedimento é evidente nas 
práticas de auto-ajuda do Geledés; nas experiências variadas de resgate das mulheres vítimas de violência doméstica ou outras modalidades de violência de gênero, levadas a cabo pela União de Mulheres; nas oficinas de reconhecimento das dificuldades encontradas na construção da identidade das mulheres, as quais interferem tanto no corpo, portanto, inevitavelmente, na saúde sexual e reprodutiva, quanto na divisão sexual do trabalho, dentre outras questões, trabalhadas pelo CDD e pela SOF.

Segundo Touraine (1997:88), "o desejo de ser um sujeito pode transformar-se em capacidade de ser um ator social a partir do sofrimento do indivíduo desgarrado e das relações entre os sujeitos", chegando a colocar em xeque as inúmeras modalidades de dominação social.

É nessa direção que caminham as entidades feministas estudadas, entre elas a CDD, ao propor superar a idéia de sacrifício das mulheres em função de uma culpa socialmente engendrada ao supostamente descuidarem de seu papel de mães, guardiãs da moral social que reforça a dominação masculina - e, em troca, introduzir a idéia de solidariedade à experiência vivida das mulheres, sugerindo a criação de espaços de liberdade, protetores do esforço de subjetivação.

Nessa perspectiva, recompor a experiência das mulheres é, ao mesmo tempo, remodelar as relações entre homens e mulheres e demais formas de interação intersubjetivas, as quais apontam para uma necessária redefinição das condutas sociais e indicam a emergência de uma nova sociabilidade, tendo a ética como parâmetro societal.

Um dos desafios para a expansão das práticas empreendidas pelos agrupamentos feministas estudados está, justamente, em convencer setores dos movimentos sociais de que o desenvolvimento de certas práticas de radicalização democrática das relações em vários planos no encaminhamento das lutas, pode se traduzir em políticas gerativas (ou generativas) (Giddens, 1994;1996), revitalizadoras do campo democrático.

Assim, numa releitura de conceitos de autores como Giddens, Touraine e Melucci (1994;1996), articula-se, aqui, a interpretação das práticas feministas estudadas como capazes de "gerar novas pautas de ação coletiva" (Melucci,1996).

Como esses autores demonstram e valorizam, os ingredientes introduzidos pelos movimentos de mulheres baseados no corpo, no 
self, na experiência, têm uma carga antagonista ao sistema, por não serem redutíveis à racionalidade instrumental, e poderem se tornar ponto de referência para os atores-sujeito da sociedade civil.

As atividades concretas não se limitam a demandas, mas trazem o desafio de reconfigurar relações em vários espaços. Nessa medida, podem conformar uma pressão social no sentido da mudança social. A ação coletiva, resultando possivelmente em movimento societal ${ }^{3}$, pode se originar dessas redes práticas de atuação do campo ético-político do movimento de mulheres, pois exercem pressão no espaço público contribuindo para conflitar a lógica dominante que engendra o conformismo.

Além do mais, essa política do sujeito, esboçada no interior das práticas sob a perspectiva de gênero, é inseparável de escolhas sociais e políticas que podem levar à configuração de um movimento por transformações sociais amplas. Como ressalta Touraine:

"Não há reconstrução possível do sujeito à margem da referência a dita ação coletiva. É por isso que o ponto central de minha reflexão é aquele em que a idéia de sujeito se liga com a de movimento social. Esta idéia contém duas afirmações. A primeira, é que o sujeito é vontade, resistência e luta e, não, experiência imediata de si. A segunda é que não há movimento social possível à margem da vontade de liberação do sujeito" (Touraine, 1997: 85).

Esse caráter antagonista contra a racionalidade instrumental é, também, assegurado quando a subjetividade é explicitamente trabalhada - tanto na busca de autonomia do sujeito, lutando para controlar “ a narrativa do self' e não se perder na indiferenciação; quanto pela não repressão no fazer, individual e de grupo, de seu próprio itinerário para a ação comum, e de construção de um sentido próprio para as lutas sociais; inclusive, tendo aí embutido, o seu potencial emocional ${ }^{4}$, cotejando a emergência de uma cidadania societal.

As práticas de autonomia das mulheres apontam para uma política do sujeito. É, na verdade, numa práxis de cidadania assim definida, que se procura constantemente construir um denominador comum com outros sujeitos na cena pública. Tais práticas são desencadeadoras de políticas 
gerativas que descortinam inúmeros processos intervenientes nos centros de poder, que asseguram a exploração, desigualdade, opressão e exclusão em diferentes níveis, sejam econômicos ou sócio-culturais. Daí seu potencial antagonista.

Esse potencial, ou campo de possibilidades, desencadeado por políticas gerativas, no sentido de Giddens, (1994) “ de fazer as coisas acontecerem (e de não esperar que se lhes aconteçam”) não assegura evidentemente um rumo inexorável para a história, mas indica que é necessário estarmos abertos às iniciativas que vêm dos sujeitos sociais para a construção de "mecanismos de democracia dialógica" (Giddens, 1994), sem negar as dificuldades políticas e confrontos a serem superados no caminho de tal empreendimento coletivo.

\section{Políticas do sujeito, políticas gerativas: a práxis de cidadania das mulheres}

As práticas estudadas levam à reflexividade - no sentido de Giddens (1991) -, em relação ao sujeito pessoal e, também, no plano coletivo - na direção de assegurar as condições sociais de realização plena da subjetividade.

Ou seja, a análise aqui empreendida está referida, antes de tudo, à importância de novas práticas que privilegiem o sujeito. É baseandose nessas novas práticas de cidadania, dentre elas as assentada nas mulheres como sujeito, que se lançam sementes para frutificação de movimentos societais, os quais, no plano político, re-significam a cidadania através das políticas gerativas que engendram.

Cada vez mais esses tipos de práticas se dirigem a projetos de vida coletivo, extrapolando a motivação inicial e restrita de que partiram, ou seja, suplantando as reivindicações específicas ou problemas localizados.

Para evidenciar isso, retomo aqui uma das oficinas de avaliação da SOF, realizada com mulheres agricultoras, como um dos momentos dessas práticas gerativas que resultam em ganho de cidadania.

A seleção de um exemplo retirado de um dos meios mais tradicionais no que se refere às relações de gênero e, sobretudo, no tocante à divisão sexual do trabalho na roça e comunidades rurais, deu- 
se no sentido de apontar os sinais de mudança social, possível quando se parte de práticas articuladas ou vivenciadas pelos sujeitos, no caso, as mulheres agricultoras.

Ressonâncias dessas práticas das mulheres agricultoras começaram a ser sentidas no sindicato rural e nos departamentos rurais da CUT e da CONTAG, que abriram-se mais à participação das mulheres agricultoras.

Essas experiências e lutas das mulheres agricultoras repercutiram numa das teses do último congresso da CONTAG:

“[...] A gestão da unidade produtiva precisa ser considerada como um exercício prático de democracia. Se todos os membros da família têm uma função e um papel no processo produtivo, eles têm direito de tomar parte nas decisões e nos resultados. Para isso é preciso valorizar o trabalho das mulheres e dos jovens na agricultura em regime de economia familiar, construindo relações sociais de gênero e geração igualitária e solidária etc." ${ }^{\prime \prime}$

Nota-se, a partir dessas práticas observadas - as quais a SOF tem contribuído para incentivar, divulgar e sistematizar -, as ressonâncias pessoais na vida das mulheres trabalhadoras rurais, e coletivas - nas associações, nas comunidades, na CUT e na CONTAG.

Observa-se o entretecer de redes de interação que geram políticas, partindo de experiências que se dão em diversos níveis - subjetivo, ou seja, de reflexividade do sujeito individual na construção de sua autonomia, e coletivo, na busca de solidariedade para a ampliação e socialização das práticas e experiências.

Neste caso acima exposto, nesta rede de atuação, cruzaram-se ativistas de ONGs - FASE, SOF -, sindicalistas da CONTAG e CUT, as próprias comissões organizadas de mulheres agricultoras do Paraná, na tentativa de gestar uma política pública para a agricultura familiar, simultânea a uma configuração mais ampla da cidadania das trabalhadoras rurais baseada nas vivências das relações sociais em que estão inseridas. Além disso, no caso analisado, o olhar introduzido pela questão de gênero mudou também o modo de se conceber a gestão da unidade produtiva.

Ao desentrelaçar (desconstruir) os padrões familiares tradicionais das práticas cotidianas de trabalho, as mulheres agricultoras que se 
organizaram e enfrentaram os riscos, se tornaram pioneiras de um novo território social aos olhos da comunidade e de si mesmas, reconstruindo formas mais arejadas de relação familiar que envolvem, ao mesmo tempo, decisões sobre o lado material da unidade produtiva. Considera-se aí, inclusive, a revisão da divisão sexual do trabalho na agricultura familiar.

Embora o sujeito individual se torne foco da ação, não quer dizer que sua atuação fique restrita a interesses pessoais, ou tem um alcance limitado, pois o que está em jogo é a qualidade da ação coletiva e até, uma nova orientação para os movimentos sociais.

Podemos ainda seguir Touraine(1997), ao analisarmos as falas de muitas mulheres que participaram de atividades junto às entidades pesquisadas, quando afirma que "é a resistência do indivíduo, seu desejo de ser ator, seu esforço de subjetivação... de poder reapropriar-se da vida social a partir de seu reposicionamento como sujeito", que se tem repensado e engendrado mudanças.

As oficinas, os grupos de auto-ajuda, os cursos de formação, as pesquisas realizadas em seu meio, são modalidades de constituição de uma política do sujeito, via itinerários concretos, colocando a articulação entre o pessoal e o coletivo, que Giddens bem definiu como sendo um dos componentes da reflexividade da modernidade, para a qual as práticas feministas continuam fornecendo alimento.

A subjetividade e a identidade pessoal (self-identity), em vários matizes, são molas impulsionadoras do que Giddens considera "reflexividade da modernidade". Ora, essa perspectiva indica que não é possível seguir adiante nos processos de mudança social sem considerar aspectos antes invisíveis ou camuflados das relações sociais: a subjetividade, a sexualidade, as relações assimétricas de poder entre o masculino e o feminino, ou a construção diferencial da identidade dos gênero e a divisão sexual do trabalho, entre outros aspectos. Esses são apenas alguns dos aspectos das questões cruciais que o movimento de mulheres tem tentado inscrever no terreno das lutas sociais.

O movimento de mulheres, portanto, ao trazer à tona a perspectiva de gênero, fortaleceu e redesenhou "novas formas de movimento social, que assinalam uma tentativa de reapropriação coletiva de áreas da vida, institucionalmente reprimidas" (Giddens, 1994). Nesse âmbito, o movimento feminista foi fundamental. 
Aponto esses dois pólos da transformação social, a subjetividade e a cidadania, como elementos chave para se pensar as transformações das relações de gênero no conjunto das relações sociais. Assim, o horizonte analítico resultará ampliado com a tematização das relações entre subjetividade e cidadania das mulheres. É nesse sentido também que as práticas feministas têm tentado ligar ações pessoais e coletivas (Silveira, 1997).

A desconstrução da lógica de dominação-exploração, presente nas relações de gênero, e a luta das mulheres para auto-apropriação de si mesmas podem ser vistas como um processo de individuação que, incorporadas à reflexão, enriquecem as análises sobre a intersecção dos planos pessoal e societal. (Melucci,1996:211).

A partir dessas referências, nota-se como a perspectiva de gênero também oferece a possibilidade de repensar os vínculos entre os aspectos micro e macro sociais. Como já foi mencionado anteriormente, uma luz se acendeu quando o movimento de mulheres mostrou que âmbitos considerados como privados (micro, portanto), como o corpo, o amor e a família, estão atravessados por relações de poder, ou seja, pelo político.

As variadas experiências contextuais observadas, propiciadas, catalizadas ou potencializadas pelas entidades pesquisadas indicam uma dinâmica subjacente que redefinem o engajamento pessoal de inúmeras mulheres de diversos setores sociais como as trabalhadoras, religiosas, ou mulheres de comunidades de base, dos setores dos movimentos populares, das mulheres negras, etc. Tal engajamento significa, muitas vezes, também um projeto reflexivo de engajamento na maioria dos assuntos fundamentais da sociedade civil.

A definição de política emancipatória é fundamental para a prática entre as mulheres. Giddens (1994:188) a define como "uma perspectiva genérica preocupada sobretudo com a libertação dos indivíduos e grupos de constrangimentos que afetam adversamente suas hipóteses de vida".

Assim, romper e ultrapassar as condições de subordinação, dominação, opressão e exclusão, tem sido um dos objetivos que as entidades feministas têm apresentado às mulheres de amplos setores sociais. Isso se dá pelo enfrentamento de poderes em vários níveis, por meio do incentivo à participação, pelo incentivo à autonomia, que funciona como um princípio mobilizador. 
As políticas da vida (Giddens, 1991;1994) repõem as mulheres no papel de protagonistas. Em primeiro lugar, da "narrativa do self' e, em decorrência disso, como protagonistas alimentadoras de uma práxis de cidadania na direção da configuração de políticas emancipatórias da sociedade.

Assim, como pude observar na pesquisa, as mulheres interpeladas pela abordagem de gênero contribuem para exercer pressão sobre a agenda política dos movimentos sociais e espaços sociais em que atuam, tanto na vida cotidiana, quanto nas lutas coletivas.

Essa pressão diz respeito à recuperação de problemas como os relativos às relações diferenciais entre homens e mulheres; os referidos ao corpo, à sexualidade; à divisão sexual do trabalho também no plano doméstico, pois antes estavam restritos ao privado e, agora, recuperados em sua dimensão pública.

Giddens explica-nos qual o sentido de "política", "em política da vida":

"É uma convenção na teoria política reconhecer uma concepção restrita e outra ampla de política. A primeira, refere-se a processos de tomada de decisão dentro da esfera governamental do Estado; a segunda, vê como políticos todos os tipos de processos decisórios que digam respeito à resolução de debates ou conflitos em que chocam interesses ou valores opostos. A política da vida é política em ambos sentidos" (1994:201).

As práticas sociais das mulheres, resultantes de inúmeras experiências coletivas, as colocam como sujeito. As práticas de gênero, impulsionadas por entidades com o perfil das entidades estudadas, por meio da autonomia como princípio de inteligibilidade de suas ações, articuladas à solidariedade, como outro princípio de engajamento junto a outros sujeitos subordinados, permitem a articulação de políticas da vida às políticas emancipatórias.

Tais cruzamentos possibilitam fazer o inventário das diversas subordinações, sejam elas baseadas em gênero, raça/etnia, classe, religião, etc., a partir do modo como operam no indivíduo, até o nível do contexto social mais amplo.

Todavia, embora o objetivo das práticas seja sempre social, a abordagem reflexiva - via entrelaçamento da identidade individual e 
grupal - restitui às mulheres o sentido de suas práticas, muitas vezes diluído num emaranhado de situações que, justamente, desconectam as dificuldades pessoais dos contextos sociais que as engendram.

Esse caminho é fundamental, sobretudo nos casos em que se enfrenta a violência de gênero; nos casos de culpa e risco com relação ao aborto; na aceitação e ocultamento do assédio sexual no trabalho; do racismo na escola, na rua, no mercado de trabalho, etc.

$\mathrm{O}$ aparecimento da questão do aborto na agenda política, por exemplo, expressa a emergência da política da vida, mas conectada em suas implicações de questionamentos de opressões limitantes das hipóteses de vida do sujeito.

Nesse, e em outros casos freqüentes no cotidiano das mulheres, sobretudo as das camadas populares, as práticas feministas abrem a possibilidade de estabelecer as conexões perdidas entre o sócio-cultural e o político, via a conformação de uma política do sujeito. Além do mais, essa política do sujeito, no que se refere às mulheres, contém o diferencial da práxis de cidadania das mulheres.

Tais ações e práticas orientadas pelas entidades feministas mediadoras, indicam a possibilidade de influenciar outros sujeitos políticos para, em conjunto, conformar uma "cidadania coletiva reflexiva" (Giddens, 1994b).

As entidades feministas estudadas, em suas diversas abordagens, têm estimulado políticas gerativas, constituindo, assim, mecanismos que apontam para o desenhar de uma democracia dialógica. Tais fatores são fundamentais para o esboço de alternativas emancipatórias da sociedade.

Nas palavras do próprio Giddens:

"Num mundo de alta reflexividade, um indivíduo deve alcançar um certo grau de autonomia de ação como condição de ser capaz de sobreviver e de modelar uma vida; mas autonomia não é a mesma coisa que egoísmo e, ademais, ela implica em reciprocidade e interdependência. A questão sobre reconstruir as solidariedades não deveria, portanto, ser vista como sendo para proteger a coesão nas bordas de um mercado egoísta. Ela deveria ser entendida como uma questão para reconciliar autonomia e interdependência nas várias esferas da vida social, inclusive no domínio econômico"(1994:18). 
As diversas práticas junto às mulheres, levadas à cabo sob a perspectiva de gênero, são exemplares dessa tentativa, acima descrita, na no esforço de articular autonomia e solidariedade.

Enquanto mecanismo de democracia dialógica, as práticas feministas freqüentemente interpelam a sociedade civil e o espaço público, indicando a necessidade de radicalizar a democracia (Giddens, 1994b:22).

Como as mulheres organizadas são as maiores incentivadoras da criação de uma arena pública para a resolução das questões que afetam a todas as mulheres, pode-se dizer que fomentam mecanismo de democracia dialógica em várias esferas, re-significando cidadania e democracia nesse processo.

Enfim novas portas se abrem, possibilitando repensar as relações entre sociabilidades dialógicas como alimentadoras de projetos emancipatórios, sem que, com isso, tenhamos que afirmar plenamente desenhados os sujeitos capazes de empreender e articular um projeto emancipatório na sociedade atual.

Contudo, temos práticas sociais que revitalizam o tecido social, apontando para a articulação dessas noções de autonomia e solidariedade como orientadoras das práticas empreendidas por um número razoável de entidades de mulheres que trabalham sobre a perspectiva de gênero, impulsionando uma práxis de cidadania que vincula cada vez mais o social e o político no tratamento dos conflitos agudos gestados numa sociedade excludente como a brasileira.

Por fim, as práticas de cidadania das mulheres podem se tornar experiências contra-hegemônicas, pois as práticas hegemônicas do capitalismo contemporâneo têm bloqueado o acesso à cidadania, engendrando cada vez mais desigualdades de poder que afetam em cheio as mulheres.

De tais práticas, podem ser retiradas energias para as lutas democráticas. São ações sobretudo de rebeldia, desafiando submissões, opressões, exclusões que desestabilizam subjetividades produzidas pelo mercado.

No sentido que lhe dá Souza Santos (1994), alternativas emancipatórias devem ser buscadas nas experiências contrahegemônicas ou na contracorrente das articulações hegemônicas, que expressam reivindicações coletivas de liberdade. $\mathrm{O}$ autor valoriza os 
grupos feministas enquanto criadores de coligações com outros sujeitos sociais, baseados em discursos, práticas e valores que procuram repactuar e redefinir coletivamente a atuação em diversos espaços.

$\mathrm{Na}$ luta dos diferentes grupos de mulheres, negras, brancas, trabalhadoras rurais e urbanas, moradoras das periferias, das classes subalternas enfim, deparamo-nos com desejos de mudança: por isso buscam-se saídas coletivas no enfrentamento das desigualdades sociais, organizadas por meio das práticas propiciadas por ativistas que traduzem essas energias inspiradoras de mudança. Nesse contexto, é plausível enxergar outras tramas possíveis para a transformação da sociedade.

$\mathrm{O}$ fato de termos diferentes sujeitos que concebem novas políticas em torno das lutas contra as desigualdades e exclusões, as quais reatualizam as críticas aos dilemas e tensões da modernidade, é indicador de outras saídas possíveis, estimuladas a partir do tecido social e inspiradoras de uma sociedade civil revigorada. Isso pode ser observado se focalizarmos cada vez mais as relações amplas que envolvem os gêneros; as concepções de direitos humanos; a ampliação da questão ecológica sobre os destinos da sociedade para os destinos do planeta, vistos como interdependentes.

A sociedade civil ganha força quando sujeitos, como as mulheres, comparecem, pois, como lembra Touraine (1997:31), "cada vez com mais frequiência denominamos sociedade civil este espaço em que se formam atores que querem ser reconhecidos como sujeitos".

Algumas ações estudadas, iniciadas inúmeras vezes como resposta concreta no cotidiano vivido pelas mulheres, reconhecidas numa ação de cidadania, acabam inclusive potencializando e alimentando a atuação das redes internacionais articuladas pelas feministas no campo dos direitos humanos.

Tais práticas, estando mais próximas da experiência pessoal na base da sociedade, mediadas pelas entidades que atuam junto a ela na perspectiva de gênero, tornam possíveis a reconstrução de movimentos societais de caráter transformativo, não meramente reivindicativo.

As lutas das mulheres contra as barreiras de gênero à cidadania plena, nos planos material e simbólico (cultural), podem ser observadas em inúmeros itinerários da práxis de cidadania das mulheres, que refletem aspectos chave para a compreensão do caráter da constituição de 
identidades políticas, baseadas no entrejogo de subjetividades que interpelam a cidadania como uma estratégia política, mas sustentada nessa tessitura societal complexa, ou seja, no seu caráter eminentemente relacional.

Enfatiza-se aqui que, para Touraine (1997), um movimento societal surge "quando há capacidade dos atores (sujeitos) elaborarem uma práxis, isto é, comprometerem-se com um conflito societal", objetivando fundar uma vida social livre.

Nesse âmbito, se encararmos a cidadania como práxis(relacional) , portanto dinâmica, em conexão com a subjetividade, identidade e experiência dos diferentes sujeitos, pode-se vislumbrar um caminho promissor que tal interpretação das práticas concretas dentre o ativismo das mulheres têm indicado, na direção de esboço de alternativas emancipatórias da sociedade na sociedade contemporânea.

A multiplicidade de práticas participativas que as entidades de mulheres se envolvem e/ou desencadeiam nos anos 90 , revela - e o exame empírico de algumas práticas dessas interlocutoras confirmou na presente pesquisa - que o capital historicamente construído do feminismo se mostra dinâmico, ao gestar-se enquanto veículo para novos projetos emergentes na sociedade, que levem em conta o reconhecimento público de múltiplos sujeitos na intersecção de relações - e identidades de classe, gênero, raça, religião, dentre outras.

Se partirmos de perscrutar e interrogar a sociabilidade humana, e esta envolvendo fortemente os gêneros, após nos depararmos com antagonismos criados pelas desigualdades e opressões históricas, mas que se apresentam no cotidiano, podemos encontrar um mapa valioso dos itinerários sociais, desde o plano pessoal ao coletivo.

Assim, não é fantasioso afirmar a existência de elementos de emancipação presentes numa realidade altamente excludente. Nessa óptica, todas as mediações aqui analisadas podem ser encontradas, partindo-se das trajetórias dos sujeitos da pesquisa.

É instigante observar como trajetórias individuais de enfrentamento pessoal de opressões podem ascender ao plano da ação organizada, redundando numa ação política e, por fim, sinalizando projetos de vida coletivos.

Na pesquisa, encontramos o caso de Deise Leopoldi ${ }^{6}$, que na sua busca por justiça no caso do assassinato cruel de sua irmã Márcia Leopoldi 
pelo namorado, a fez encontrar no espaço público, uma aliada - a União de Mulheres -, que potencializou sua luta contra tal violência e permitiu uma ancoragem social e uma releitura de sua própria experiência pessoal de relações de gênero opressivas. Tal encontro, por fim, permitiu reinscrever sua postura no contexto dos direitos humanos das mulheres e ancorar sua prática pessoal numa participação de cidadania num contexto coletivo.

Ao confrontar sua subjetividade pessoal e a de outras mulheres na luta contra a violência de gênero, redesenhou as relações na interação com outras mulheres por reconhecer sua problemática como coletiva.

Mesmo que a entrevistada não se apresente como uma ativista de primeira linha (o que efetivamente ela foi, na sua busca inflexível por justiça) na demanda pelos direitos humanos das mulheres, sua inserção e esforço pessoal já permitiu uma ação institucional dos movimentos por esses direitos, encaminhando à OEA como exemplo da impunidade da violência de gênero no país. Por intermédio da União de Mulheres, em sua prática de acompanhamento de casos exemplares de violência contra as mulheres, tornou-se possível elucidar a ação da justiça e do Estado, e a conseqüente responsabilidade política e social dos mesmos em elaborar políticas públicas de combate à violência de gênero para o seu enfrentamento.

Essa política do sujeito empreendida pelas mediadoras da práxis de cidadania das mulheres, ao conectar o plano pessoal e o coletivo, abre novas possibilidades para a ação política emancipatória. Em outros termos, o princípio de autonomia tão caro ao movimento de mulheres, diz respeito ao desenvolvimento da habilidade para a atuação das mulheres como cidadãs críticas. A idéia de sujeito, portanto, se torna central para o entendimento da cidadania aqui postulada.

Um chão comum de sociabilidade, base para uma cidadania societal, portanto, re-significada, quer nos levar a pensar "o conjunto das relações sociais na sua simultaneidade" (Kergoat), enfoque induzido pelo olhar de gênero. Pode-se dizer, deste ângulo, que interpelam a cidadania sem a necessidade de obscurecer a face dos sujeitos em interação.

Melucci nos adverte que os sociólogos têm apresentado "uma miopia do presente", talvez sintoma de tempos em que não há um novo horizonte configurado, ou da famosa sensação de "fim da história", efeito ideológico desencadeado no âmbito de processos sócio-econômicos 
hegemônicos. Essa miopia refere-se à dificuldade de visualização efetiva do campo de possibilidades de mudança, mas já vislumbrado em determinadas ações coletivas ou redes de movimentos sociais, ainda que submersas na maioria das vezes. Nessa mesma direção, Touraine (1997) nos alerta: "Que o vazio da cena política mundial não nos impeça de ver que os bastidores da história estão cheios de vida".

$\mathrm{Na}$ conjuntura histórica que estamos vivendo, na realidade social brasileira excludente que engendra o confisco da cidadania, as práticas estudadas sinalizam com sua face dialógica e gerativa, de cooperação em direção às forças sociais de um campo democrático e popular, e de conflito (recusa) face aos processos institucionais e políticos refratários à participação democrática.

É um desafio pensar, nos dias atuais, exatamente numa cidadania como processo dinâmico (práxis) impulsionado por políticas dos sujeitos que, justamente, conformariam uma cidadania societal capaz de recusar a capitulação a uma ordem social excludente e confrontar visões estabelecidas de democracia e cidadania que não arranham sequer o status dos poderes estabelecidos e suas tecnocracias operantes.

\section{Notas}

${ }^{1}$ Este texto compõe o capítulo 5 de minha tese de doutorado "Itinerários de Gênero e Re-significação da cidadania" [apresentada à $\mathrm{PUC} / \mathrm{SP}$, em abril de 1999].

${ }^{2}$ No último ano da pesquisa (1997) ocorre uma cisão em Geledés, surgindo uma outra ONG - Fala Preta cujas participantes são oriundas do Programa de Saúde da Mulher Negra do Geledés. Tal fato criou um problema para a pesquisa, pois as principais entrevistas se deram com mulheres do Programa de Saúde em função das práticas selecionadas que procuravam trabalhar a construção da identidade da mulher negra, No entanto, seria incorreto substituir o nome da entidade pesquisada para Fala Preta, pois no processo anterior se construiram enquanto Geledés. Além do mais, seria impossível realizar uma nova pesquisa com uma ONG recém nascida; não obstante, o "capital social" que levavam é o mesmo apreendido nas práticas do programa de saúde do Geledés. Assim, na tese, optei por trabalhar a ênfase em Geledés no programa de saúde e apresentar algumas das tensões perceptíveis que teriam levado aos desdobramentos ocorridos. 
${ }^{3}$ Para Touraine (1997, p.104), um movimento é societal quando carrega uma nova proposta de sociabilidade, pondo, principalmente, em questão, uma forma de dominação social: "combinam um conflito propriamente social com um projeto cultural, que sempre se define com referência a um sujeito".

${ }^{4}$ Cf. Barbalet (1998), Emotion, social theory and social structure. A Macrosociological approach. London: CUP. Nesse livro o autor examina aspectos da estrutura e dos processos sociais, analisando categorias emocionais, apontando para a centralidade das emoções nas interações sociais, suplantando as abordagens que as relegam ao nível micro e fazendo uma releitura da teoria sociológica à luz dessa problemática. Ver também Giddens (1994), onde ressalta a possibilidade de uma democracia das emoções como elemento de um contexto reflexivo que apontaria para uma democracia dialógica. No âmbito da teoria feminista, consultar, entre outros estudos, Jaggar, A "Amor e conhecimento : a emoção na epistemologia feminista". In (orgs) Jaggar, A e Bordo, S. Gênero, corpo, conhecimento. Rio de Janeiro: Rosa dos Tempos, 1997.

${ }^{5}$ Apud Lisboa, M.E. in Cadernos Sempre-viva, $n^{\circ} 2$.

${ }^{6}$ Cf. entrevista realizada em 19/05/97.

\section{Referências Bibliográficas}

ALVAREZ, S; DAGNINO, E. e ESCOBAR, A. The Cultural and the political in Latin American social movements: Introduction. (eds) ALVAREZ, S.; Dagnino, E. e Escobar, A Cultures of Politics, Politics of Cultures. Oxford/Colorado: Westview Press, 1998

BARBALET, J. M. A Cidadania. Lisboa: Editorial Stampa, 1989.

BARBALET, J.M. Emotion, Social Theory, and Social Structure. A macrosociological approach. UK: CUP, 1998.

BONACCHI, G. E GROPPI, A (orgs) O dilema da cidadania. São Paulo: Ed. UNESP, 1995

BRUSCHINI, C. e COSTA, A (orgs) Uma questão de gênero. Rio de Janeiro: Rosa dos tempos. São Paulo: Fundação Carlos Chagas, 1992

CASTRO, M. Alquimia de categorias sociais na produção de sujeitos políticos. Estudos feministas. Vol.0,n.0. Rio de Janeiro: CIEC/ECO/UFRJ, 1992

CASTRO, M. No limiar de um novo milênio: possibilidades e cenários. Cadernos CRH, n.22, Salvador, 1995. 
CASTRO,M. e ABRAMOVAY, M. Gêneros de poder: Engendrando um novo feminismo desde as bases. Brasília/DF: UNESCO/ CEPIA. Mimeo, 1997.

COSTA, S. Contextos da construção do espaço público no Brasil. Novos Estudos CEBRAP.n.47, março 97. São Paulo:CEBRAP, 1997.

DONATI, P. Identity and Solidarity in the complex of citizenship: The relational approach. Journal of International Sociological Association.vol.10, n.3,spt.95, 1995.

FRASER,N. Repensar el ambito público: una contribución a la critica de la democracia realmente existente. Debate Feminista.marzo/93. Mexico, 1993.

GIDDENS, A. As conseqüências da modernidade. São Paulo: Ed. UNESP, 1991.

GIDDENS, A A transformação da intimidade. São Paulo: Ed. UNESP, 1993.

GIDDENS, A Modernidade e identidade pessoal. Oeiras: Ed. Celta, 1994.

GIDDENS, A Admirável mundo novo: O novo contexto da política. Cadernos CRH., n.julho/dez.94, Salvador, 1994 b.

HABERMAS, J. L'espace publique, 30 ans aprés. Quaderni, n.18, automne92, 1992.

HELLER, A História y Futuro. Barcelona: Península, 1991.

KERGOAT,D. Relações sociais de sexo e divisão sexual do trabalho. (orgs.) Lopes,M.; Meyer, D. e Waldow, V. Gênero e Saúde. Porto Alegre: Artes Médicas, 1996.

LISTER, R. Citizenship. Feminist Perspective. London: Macmillan Press, 1997.

MELUCCI, A A experiência individual na sociedade planetária. Lua Nova.n.38. São Paulo: CEDEC, 1996.

SILVEIRA,M.L. Contribuições da perspectiva de gênero para o esboço de alternativas emancipatórias da sociedade. (orgs.) Baptista, D.; Silveira,M.L. et alii Cidadania e Subjetividade. São Paulo: Imaginário, 1997.

SOUZA SANTOS,B. Pela mão de Alice. O social e o político na pós modernidade. Porto : Afrontamento, 1994.

TOURAINE, A. Podremos vivir juntos? Iguales y diferentes? Mexico: Fondo de Cultura Económica, 1997. 


\section{Resumo}

$\mathrm{O}$ artigo analisa práticas de cidadania das mulheres por meio dos itinerários de atuação de algumas entidades mediadoras da ação coletiva das mulheres nos anos 90. Tal análise indica uma práxis de cidadania que ao introduzir diferentes imbricações de gênero, raça/etnia e classe no espaço público contribui para a emergência de uma cidadania societal. Tais práticas trazem o foco para uma política do sujeito no enfrentamento de situações concretas de subordinação, desigualdade e exclusão.

Palavras-chave: relaç̃es de gênero; cidadania societal; políticas do sujeito.

\section{Abstract}

The article analyses many practices of women citizenship through the observation of some women groups and associations performance in the 90's. The article explain the existence of a citizenship praxis that introduce diferentes inetersections of gender, race/ethnicity ad class in the public space. The principal argument tries to explain the emergency or the rise of a societal citizenship: these practices brought the focus to a subject politics against practical situations of subordinations, inqualities and exclusion that revitalize wome societal networks.

Key words: subject politics; gender relationships; societal citizenship. 